\title{
Oncology Research and Treatment 2020: Past, Present, and Future
}

\author{
Sylvie Lorenzen ${ }^{a} \quad$ Ralf-Dieter Hofheinz ${ }^{b}$ \\ ${ }^{a}$ Medizinische Klinik III, Klinikum rechts der Isar, Technische Universität München, München, Germany; \\ bInterdisziplinäres Tumorzentrum, Universitätsmedizin Mannheim, Universität Heidelberg, Mannheim, Germany
}

Exactly 20 years ago, in the year 2000, the journal Onkologie, founded in 1978 by Karger Publishers, was first listed in MEDLINE during the editorship of Prof. Dr. Wolfgang Queißer (Mannheim, Germany). On that memorable day, the young assistant Ralf Hofheinz heard a shout from his boss' office, followed by quick steps, and a few seconds later he was hugged by Wolfgang Queißer with the words "We are in MEDLINE!"

In 2002, Prof. Dr. Hans-Joachim Schmoll (Halle, Germany) took over the responsibility of chief editor and successfully continued the strategy to establish Onkologie as an interdisciplinary clinical oncological journal. In 2014, 6 years ago, Onkologie finally received its current name Oncology Research and Treatment during the editorship of Prof. Dr. Michael Hallek (Cologne, Germany). This change of name was part of an agenda promoting the internationalization of this traditional journal focusing on clinical and translational research.

During the editorship of Prof. Hallek, the journal has continuously increased its international visibility. This is, for instance, reflected in the fact that submissions from 43 countries all over the world have been received during the past 12 months (April 2019 to April 2020). A total of 749 unique manuscript submissions were received during this year. The vast majority of these submissions are original research articles (553; 74\%). Compared to 217 articles received in 2015, this accounts for a $350 \%$ increase over a 5-year time span! Likewise, the number of downloads of articles has more than doubled during the past 4 years, amounting to 391,000 in 2019. Decisions have been made about 640 manuscripts during the past year, and the acceptance rate was $11 \%$. In other words, the rejection rate as a sign of the increased quality of the journal has risen from around $70 \%$ in 2011 to $89 \%$ in 2020 . The average handling time for all manuscripts from submission to final decision is 1.5 months when considering all manuscripts, and 4.5 months for the manuscripts that are accepted.

The journal covers the entire field of clinical and translational oncology including diagnosis and supportive and palliative care. Oncology Research and Treatment continues to be considered the official journal of oncological societies and working groups such as the German and Austrian Societies of Hematology and Oncology (the DGHO and OeHO), the Swiss Society for Hematology (SGH/SHH), the Working Group of Medical Oncology within the German Cancer Society (AIO), and the German Fatigue Society (DFaG).

We feel privileged to continue working on what Prof. Hallek achieved with the editorial team and all the associated editors and reviewers in recent years. Our commitment is to further promote the visibility and quality of Oncology Research and Treatment and to strengthen its role as a nationally and internationally acknowledged 
journal. Moreover, we will strive to improve awareness of this journal within the group of young(er) medical oncologists and scientists as a platform for communicating their research results.

With an editorial board of experts who are leaders in their field, Oncology Research and Treatment aims at delivering a broad and up-to-date overview of the fast-moving and continually evolving global oncology landscape. Our future perspective is to maintain the high standard of this journal, further expand our editorial team to include internationally recognized experts, and provide rapid and efficient peer-review publications about inno- vative cancer treatments. This will ultimately only work successfully if you, the readers and contributors to this journal, continue to share with us your scientific knowledge, notions, and critical thoughts. We look forward to a fruitful collaboration!

Sylvie Lorenzen and Ralf-Dieter Hofheinz

\section{Disclosure Statement}

The authors have no conflicts of interest to declare. 